\title{
Semantic constraints on multiple case marking in Korean
}

\author{
Byong-Rae Ryu
}

This paper presents a first attempt to offer a comprehensive typology of the pairs of identical-case marked NPs in Korean. On the basis of such semantic relations between two consecutive NPs like meronymic relation, inclusion relation, quantity-quality relation, spatio-temporal relation, and predication relation, we identify 16 types of these pairs, and propose each type as a licensing condition on double case marking. We argue that the multiple case marking constructions are merely the sequences of double case marking, which are formed by dextrosinistrally sequencing the pairs of the same-case marked NPs of same or different type. Some appealing consequences of this proposal include a new comprehensive classification of the sequences of same-case NPs and a straightforward account of some long standing problems such as how the additional same-case NPs are licensed, and in what respects the multiple nominative marking and the multiple accusative marking are alike and different from each other.

\section{Introduction}

Despite numerous studies of the so-called multiple case marking constructions (MCCs), there still remain more puzzles unsettled than already solved. There have been only a few scattered attempts to explore the whole range of data in a balanced way. The majority of the previous studies have mainly or exclusively focused on the double nominative constructions (DNCs), missing the crucial points concerning the questions of how DNCs are related to the multiple nominative constructions (MNCs) on the one hand, and to the double accusative constructions (DACs) on the other (see Section 2.2). Furthermore, the question of how DACs are related to the multiple accusative constructions (MACs) still remains to be answered in Korean linguistics. 
The latter two questions about double and multiple accusative marking arise out of the observation that multiplication of identical case marking is not confined to the nominative case. It can also be observed in accusative, and dative case marking contexts, as well as in other semantic case marking contexts such as the locative, instrumental, goal, and source cases (see Section 4.2). It has been touched on from time to time that multiple accusative marking is more restrictive than multiple nominative marking (cf. Cho 2003, Cho \& Lee 2003, Chae \& Kim 2008, among others). However, the question of in what respects the multiple nominative marking and the multiple accusative marking are alike and different from each other has not been explored in detail.

It is well-known that not all the sequences of NPs marked with identical case markers - be it nominative or accusative - are grammatical. This fact drives us to the question of why and how sequences of identical case-marked NPs are licensed. Little attention has been paid so far, however, to this licensing issue (see 2.2 for a critical review). We believe that a satisfactory solution of this licensing issue is a starting point for understanding the exact nature of MCCs better.

The purpose of this paper is twofold. Tackling this licensing issue, we argue that there are at least 16 types of sequences of same-case NPs in Korean on the one hand. On the other, we try to find an answer to the question of in what respects the multiple nominative marking and the multiple accusative marking are alike and different from each other. We explore comprehensive data including some less frequently discussed ones, and identify 16 lexical semantic relations as licensing conditions on identical case marking. After showing that all these types are attested in MCCs, we argue that MCCs are formed by dextrosinistrally sequencing the pairs of the same-case marked NPs of same or different type. We propose a set of licensing conditions from a lexical semantic point of view. We further argue that the two consecutive NPs are identically case-marked via case sharing: More specifically, two NPs share nominative cases if they stand in one of the 16 semantic relations, and they share accusative cases, if they stand in one of the 10 semantic relations. 6 out of 16 relations are not attested in the accusative case marking contexts.

This paper is organized as follows: In Section 2, we first present some key properties of identical case marking phenomena in Korean, and then critically review some previously proposed leading ideas. In Section 3, we argue that at least 16 semantic types of sequences of identical case-marked NPs should be assumed, showing that all these types are attested in MCCs. In Section 4, we 
propose the 16 semantic relations as licensing conditions for case multiplication, and argue that multiple case marking is simply case sharing between the two consecutive NPs standing in one of the 16 semantic relations. After we show in what respects the multiple nominative and accusative constructions are similar and different from each other, we finally draw a conclusion in Section 5.

\section{Data and issues}

\subsection{Basic properties}

Given the common assumption that there is at most one subject per clause, the multiple occurrences of subject-like, nominative-marked NPs are puzzling. This puzzling phenomenon can be noticed in various constructions in Korean, most notably in the so-called Double Nominative Constructions in (1). ${ }^{1}$

(1) $\left[\mathrm{NP}_{2}\right.$ ttokki-ka $]\left[\mathrm{NP}_{1} k w i-k a\right] k i l-t a$.

rabbit-NOM ear-NOM be.long-DECL

'The ears of rabbits are long. (lit.)' = 'Rabbits have long ears.'

At first glance, it is tempting to seek a pure representation of the theta structure of (1) in the clause (2), where the first NP is marked with genitive, occurring within the projection of the second NP.

(2) [NP $_{\mathrm{N}}$ tokki-uy $\left.k w i-\mathbf{k a}\right] \quad k i l-t a$.

rabbit-GEN ear-NOM be.long-DECL

'The ears of rabbits are long.'

The sentence (2) shows that the predicate kilta (to be long) is intransitive, and that the NP immediately preceding the predicate is the argument of the predicate. It follows from this observation that two nominative case-marked NPs, one of which is not an argument, occur in an intransitive clause in (1).

What makes the things more complicated is the fact that the number of the same-case NPs is not limited to two. Although it may not be indefinite for some mainly cognitive and/or process-related - reasons, more than two same-case NPs

1 The nominative case markers $-k a$ and $-i$ and the accusative case markers $-l u l$ and $-u l$ are allomorphs, respectively. The former is post-vowel and the latter post-consonantal. The Yale Romanization System is used for the romanization of the Korean words. The abbreviations for the glosses used in this paper are as follows: NOM (nominative), ACC (accusative), GEN (genitive), DAT (dative), PRES (present tense), PAST (past tense), NLZ (nominalizer), REL (relative clause marker), DECL (declarative), QUE (question), LOC (locative), INST (instrumental), CL (classifier), GOAL (goal), TMP (temporal), SRC (source), HON (honorification), sUF (suffix), FOC (focus), and TOP (topic). 
may occur in a clause, as shown in (3) (see Choe 1987, Kim 1989, 1990, Maling \& Kim 1992, Park 2001, among many others).

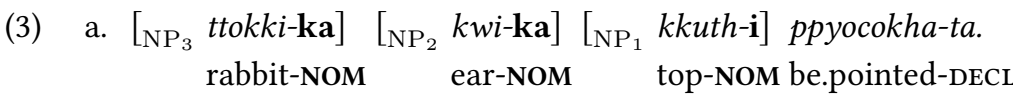

'The tops of the ears of the rabbit are pointed.'

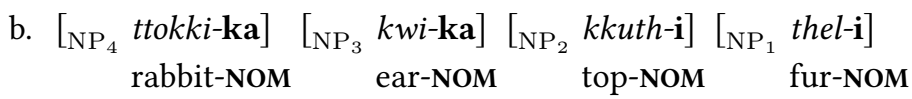
kil-ta.

be.long-DECL

'The fur of the top of the ears of the rabbit is long.'

The sequences of same-case NPs can be observed not only in nominative case marking contexts like in (1) and (3), but also in accusative case marking contexts, as in (4).

(4) Hans-ka $\left[_{\mathrm{NP}_{3}}\right.$ ttokki-lul $]\left[{\left[\mathrm{NP}_{2}\right.} k w i-\mathbf{l u l}\right]\left[\mathrm{NP}_{1} k k u t h-\mathbf{u l}\right]$ cap-ass-ta. Hans-NOM rabbit-ACC ear-ACC top-ACC grab-PAST-DECL 'Hans grabbed the top of the ears of rabbits.'

Multiple case marking is observed in the clauses formed with various predicate types including intransitive stative verbs shown in (1) and (3), transitive verbs (4), ditransitive verbs (5), and activity verbs (6). The examples (1) and (3)-(6) clearly show that, contrary to the previous claims (e. g., in Kim, Sells \& Yang 2007 among others, see also Kim 2000 for a similar claim), multiple case marking is not confined to the stative verbs.

(5) Hans-ka na-eykey $\left[\mathrm{NP}_{2}\right.$ haksayng-ul] $\left[\mathrm{NP}_{1}\right.$ yehaksayng-ul] Hans-NOM I-DAT student-ACC girl student-ACC ponay-ess-ta. send-PAST-DECL

'Hans sent me girl students of students.'

(6) $\left[\mathrm{NP}_{2}\right.$ haksayng-i $] \quad\left[\mathrm{NP}_{1}\right.$ yehaksayng-i $]$ o-ass-ta. student-NOM girl student-NOM come-PAST-DECL

'Girl students of students came.'

More than one nominative case-marked NP and more than one accusative casemarked NP can occur in a single transitive clause, as shown in (7). 
(7) $\left[\mathrm{NP}_{12}\right.$ haksayng-i $] \quad\left[\mathrm{NP}_{11}\right.$ yehaksayng-i $] \quad\left[\mathrm{NP}_{23}\right.$ ttokki-lul $]\left[\mathrm{NP}_{22}\right.$ student-NOM girl student-NOM rabbit-ACC

$k w i-\mathbf{l u l}]\left[\mathrm{NP}_{21} k k u t h-\mathbf{u l}\right]$ cap-ass-ta.

ear-ACC top-ACC grab-PAST-DECL

'Girl students of students grabbed the top of the ears of rabbits.'

Multiple case marking is noticed not only in an active clause, but also in a passive clause. The sentence (8) is a passive counterpart of the active sentence $(7) .^{2}$

(8) $\left[\mathrm{NP}_{23} t h o k k i-\mathbf{k a} /{ }^{*}-\mathbf{l u l}\right] \quad\left[\mathrm{NP}_{22} k w i-\mathbf{k a} /-\mathbf{l u l}\right] \quad\left[\mathrm{NP}_{21} k k u t h-\mathbf{i} /-\mathbf{u l}\right] \quad\left[\mathrm{NP}_{12}\right.$ rabbit-NOM $/{ }^{*}$-ACC ear-NOM/-NOM top-NOM/-ACC

haksayng-eykey] [ $\mathrm{NP}_{11}$ yehaksayng-eykey] cap-hi-ess-ta.

student-by girl student-by grab-PASS-PAST-DECL

'The top of the ears of rabbits were grabbed by girl students of students.'

It is important to note that not all sequences of the same-case marked NPs are grammatical. The occurrence of the same-case marked NPs is not arbitrary, and the order of the same-case marked NPs is not random in many subtypes of the multiple case marking constructions. Scrambling of the same-case marked NPs is highly restricted, and generally results in ungrammaticality of the clause, as shown in (9).
a. $\left[_{\mathrm{NP}_{3}} M a r y-\mathbf{k a}\right]\left[{ }_{\mathrm{NP}_{2}}\right.$ chinkwu-ka $]\left[{ }_{\mathrm{NP}_{1}}\right.$ sanguy-ka $] k h u-t a$. Mary-NOM friend-NOM jacket-NOM be.big-DECL 'The jacket of (a) friend of Mary is big.'
b. ${ }^{*}\left[\mathrm{NP}_{3}\right.$ Mary-ka $]\left[\mathrm{NP}_{1}\right.$ sanguy-ka $]\left[{ }_{\mathrm{NP}_{2}}\right.$ chinkwu-ka $]$ khu-ta. Mary-NOM jacket-NOM friend-NOM be.big-DECL

So far, we have illustrated some core properties of the data we are dealing with. They are summarized as follows:

P1 Nonargument: Only one of the nominative case-marked NPs is the argument of the predicate, occurring in the subject position, and only one of the accusative case-marked NPs is the argument of the transitive predicate, occurring in the direct object position. All the other additional same-case NPs are nonargument.

2 There are some claims that Korean has no passive constructions, unlike English or German. But it is clear in (8) that there is a construction in which a direct object argument is promoted to subject in the relevant nonactive sentences and the subject argument is demoted to the so-called agentive PP. 
P2 Multiplicity: The number of the consecutive same-case NPs are not confined to two, but may be basically infinite.

P3 Nominative/Accusative marking: Multiple occurrences of the same-case NPs are not restricted to nominative case marking contexts (i. e., in subject position), but observed also in accusative case marking contexts (i. e., in direct object position).

P4 Semantic Regularity: In many subtypes of MCCs, the semantic relations between the two consecutive NPs turn out to be identical in the nominative case marking contexts and in the accusative case marking contexts.

P5 Predicate-independence: Multiple case marking is observed in the clauses formed with various predicate types including intransitive stative verbs, transitive verbs, ditransitive verbs, and activity verbs.

P6 Voice alternation: The semantic relations between the two consecutive NPs remain unchanged in the active and passive voice.

P7 Licensing condition: The multiple occurrences of the same-case marked NPs are not arbitrary or random, but systematic.

The core property $\mathbf{P 1}$ is one of the most important criteria for distinguishing MCCs from some other constructions in which two consecutive NPs happen to be marked with the same-case marker. While additional same-case marked NPs do not saturate the valency of a predicate in MCCs, there are some constructions in which two identically case-marked NPs are subcategorized by a predicate, as can be seen in the psych-verb constructions in (10) and the copulative constructions in (11).

*(Fohn-i) *(holangi-ka) silh-/musep-/cikyep-ta. John-NOM tiger-NOM dislike-/fear-/be.tired.of-DECL ‘*(John) dislikes/fears/is tired of tigers.' (psych-verb constructions)

(11) *(mul-i) *(elum-i) toy-ess-ta. water-NOM ice-NOM become-DECL ‘*(Water) became ice.'

(copulative constructions)

Such examples as in (10) and (11) have been regarded as a type of MCCs in some studies (e.g., Rhee 1999, Park 2001, and Cha 2008, among others). It is clear, however, that they do not share the core property P1, since deletion of one NP results in ungrammaticality. They do not show the core properties P3, P4, P5, 
P6 and P7, either. For these reasons, we are not concerned here with psychverb constructions or copulative constructions containing two same-case NPs, and propose that they be excluded from MCCs. ${ }^{3}$ The only property they share with MCCs is P2, which is not a sufficient condition for being MCCs.

In the same vein, it is worth noting that the applicative formation as shown in (12b) should be distinguished from MCCs, in that the promoted argument Maria in (12b) - is an argument of the predicate.
a. Hans-ka Maria-eykey kkoch-ul cwu-ess-ta. Hans-NOM Maria-DAT flower-ACC give-PAST-DECL 'Hans gave Maria flowers.'
b. Hans-ka Maria-lul kkoch-ul cwu-ess-ta. Hans-NOM Maria-ACC flower-ACC give-PAST-DECL 'Hans gave Maria flowers.'

For this reason, we suggest that examples like in (12b) are not MCCs. ${ }^{4}$

\subsection{A critical review of some previous main ideas}

\subsubsection{Double nominative/subject constructions}

Sentences like (1) have been received much attention in Korean linguistics, as the long list of references of this paper already suggests. They have been examined under various terms such as Double Nominative Constructions (Cho 1999, Cha 2008, Choi 2012, Kang 1987), and Double Subject Constructions (Yoon 1987, 2007). Whatever term one may choose, it should be pointed out that the studies exclusively focusing on the clauses with two nominative case-marked NPs have difficulties in explaining the core properties P2, P3, and P5.

Examples like (1), (3), (6), (7), and (8) drive us to one of the key questions whether all nominative-marked NPs are subjects, and if not, what is the grammatical status of the nominative-marked nonsubject NPs. Regarding this question, two main streams of proposals are basically discernible.

3 This is not to say that these two constructions may not involve sequences of identical case marked NPs. Since they show the core property P2, it is possible to add additional nominative NPs to the position preceding the first or the second NP. In other words, the two constructions can be MCCs, if more than three identical case-marked NPs occur. See Section 4 for further discussions.

4 One might ask whether or not there is any case where MACs have no counterpart in MNCs. The example set (12) might be regarded as one of the cases. But it is not an example of MCCs, as discussed above. So we may draw a conclusion that there is no case where MACs have no counterpart in MNCs. I thank Yong-hun Lee (p.c.) for pointing out this aspect of MCCs. 
One stream maintained that both $\mathrm{NP}_{1}$ and $\mathrm{NP}_{2}$ are subject, trying to define various notions of subject: e. g., Yu (1909) called them big and small subject, Yoon (2004, 2007) major and grammatical subject, and Lee (2007) subject [Spec, RefP] and subject [Spec, TP], respectively. ${ }^{5}$ The other stream posited that only the right-most NP is subject, proposing that the left-most NP is topic or focus: e. g., Hong (1991) topic vs. subject; Rhee (1999) topic/focus vs. subject; Schütze (2001), Kim (2000, 2001), and Kim, Sells \& Yang (2007) focus vs. subject; Park (2001) focused subject vs. subject; Choi (2012) sentential specifier vs. subject.

But there remain many essential problems unsolved in the first stream of thought, as partly pointed out by Chae \& Kim (2008) among others.

First of all, a clause with more than one subject is highly odd from a perspective of theory of grammar.

Second, there is no straightforward answer to the question of what the logical structure of the clause looks like. In other words, there are clear difficulties in answering the question as to how the clauses can be interpreted in this view.

Third, there is no convincing independent evidence for assuming the various notions of subject - be it 'big' or 'small', or 'major' or 'grammatical' - crosslinguistically as well as just in this language. Additionally, it is pointed out that the relationship between the various notions of subject is extremely vague (See Yoon 2004, 2007 for a series of efforts to define these two notions of subject). ${ }^{6}$

Fourth, the multiple subject view has difficulties in finding any clear answer to the status of the third and fourth NP. For example, the grammatical status of $\mathrm{NP}_{3}$ and $\mathrm{NP}_{4}$ in (3) remains unclear in the first main stream of thought. In other words, they have difficulties in explaining the core property P2.

Fifth, unduly evaluated in the first main stream of thought is the observation that multiple case marking is possible in the accusative case marking contexts as well as in the nominative case marking contexts, as pointed out in P3, P4, P5, and P6. For the multiple accusative case marked NPs, as observed in (4), (5), and (7), further notions such as 'major object' and 'grammatical object' would be needed.

For these reasons, any attempt to wrestle with the various notions of subject or exclusively with the clauses only with two nominative case-marked NPs may result in confusion of the issue at point.

5 Choi (2008) differentiated two types of DNCs. In one type, the first nominative nominal is a grammatical subject, while the second one is a complement. In the other,both nominals are subjects, as a specifier of an IP or an AgrP.

6 Yoon $(2004,2007)$ proposed subject-to-object raising and nominative case marking as diagnostics for 'major subjects,' and subject honorification and equi-controller in obligatory control as diagnostics for 'grammatical subjects.' 


\subsubsection{Focus/Topic}

There are many unsettled problems also in the second main stream of thought. Kim (2001) claims that the sentence-initial nominative is the realization of information focus, as speculated in previous literature (Yoon 1997, 1989, O'Grady 1991, Lee 1994, Schütze 1996, among others). One of the main arguments he presented is the observation that only the first nominative case $-i /-k a$ marked phrase can be wh-questioned, as shown in (13a). It is not allowed to wh-question the second one as shown in (13).
a. Nwu-ka apeci-ka kyoswu-i-si-ni? who-NOM father-NOM professor-COP-HON-QUES
'(lit.) Who is it whose father is a professor?'
b. *John-i nwu-ka kyoswu-i-si-ni? John-NOM who-NOM professor-COP-HON-QUES '(lit.) John's 'who' is a professor?'

However, it is highly questionable how the notion of focus/topic can be extended to the non-sentence-initial, non-preverbal nominative NPs (i. e., $\mathrm{NP}_{2}$ in (3a), and $\mathrm{NP}_{2}$ and $\mathrm{NP}_{3}(3 \mathrm{~b})$ ). The contrast in grammaticality between (14a) and (14b) suggests that these notions be applied only to the first NP among the sequences of the same-case NPs. In sum, the second main stream of thought faces difficulties in explaining the core property $\mathbf{P} 2$, too.
a. $\left[\mathrm{NP}_{3}\right.$ mues-i $] \quad\left[\mathrm{NP}_{2} k w i-\mathbf{k a}\right]\left[{ }_{\mathrm{NP}_{1}} k k u t h-\mathbf{i}\right]$ ppyocokha-ni? what-NOM ear-NOM top-NOM be.pointed-QuEs
'(lit.) What is it whose top of the ears is pointed?'
b. ${ }^{*}\left[\mathrm{NP}_{3}\right.$ mues-i $] \quad\left[\mathrm{NP}_{2}\right.$ mues-i $] \quad\left[\mathrm{NP}_{1}\right.$ kkuth-i $]$ ppyocokha-ni? what-NOM what-NOM top-NOM be.pointed-Ques

Furthermore, it is highly unclear how the notion of focus/topic can be applied to the accusative case-marked NPs (i. e., $\mathrm{NP}_{2}$ and $\mathrm{NP}_{3}$ in (4), and $\mathrm{NP}_{2}$ in (5)), simply because the proponents of this view exclusively examined the double nominative/subject constructions. We can speculate that such notions may be applied only to the first NP among the sequences of the accusative-case marked NPs, as the contrast in grammaticality between (15a) and (15b) suggests. 


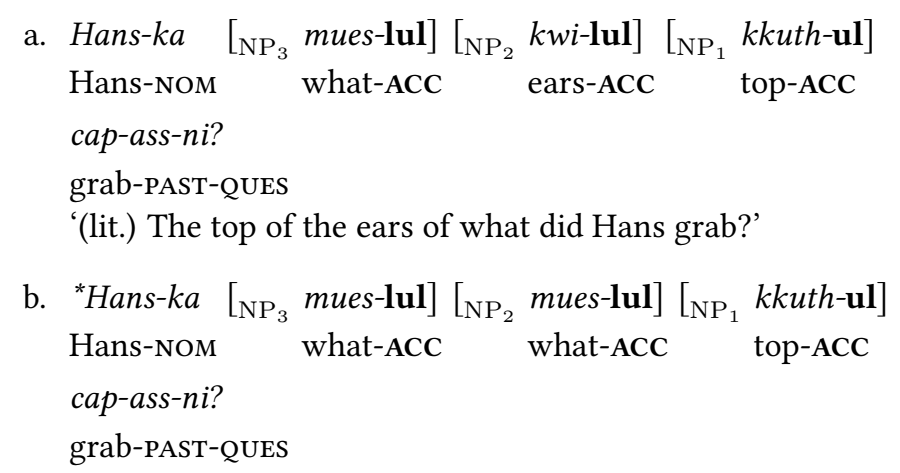

Based on the discussion above, it is safe to draw the conclusion that the second main stream of thought faces difficulties in explaining the core properties P2, P3, P4, P5, and P6. This gives us enough reason to believe that one might miss the point if one were to exclusively deal with the double nominative constructions. At the same time, this allows us to assume that double nominative constructions should be examined in more general contexts of multiple identical case marking in Korean linguistics. Therefore, a promising approach to this topic should cope not only with double nominative constructions, but also with clauses with more than two same-case NPs - MNCs and MCCs - in a balanced way.

\subsubsection{Double vs. multiple and nominative vs. accusative}

It is interesting to note that the majority of the previous works with the terms of multiple nominative/subject constructions and multiple accusative/object constructions have mainly, if not exclusively, focused on the double nominative/subject constructions and double accusative/object constructions (for MNCs see Yim 1984, Choe 1987, Choi 1988, Youn 1990, Gerdts 1991/2000, Kim 1996, Jang 1998, Koh 1999, Moon 2000, Park 2001, Kim 2001, Hong 2001, Suh 2003, Kim, Sells \& Yang 2007, Choi 2008, and Lee 2008; see Bak 1992 and Kim 2006 for MACs). It is undeniable that the question of how MCCs and DMCs are related with each other remains blurred in the majority of the previous works with the exception of only a few, e. g., Yang (1972), Park (2001), and Kim (2001) among others.

There are, however, many pieces of evidence for the insight that multiple case marking is systematically possible in the object as well as in the subject position. This shows that, contrary to the prevailing views, multiple case marking is restricted neither to stative verbs nor to the sentence-initial position. It has been touched on from time to time but not explored in detail that the multi- 
ple accusative marking is a little more constrained than the multiple nominative marking (e. g., in Bak 1992, Lee 1994, Choi 2008 among others).

\subsubsection{Possession as generative source}

Sentences like (1) and (3) have been examined under terms like inalienable possession constructions (Choi 2007, Yoon 1997), possessor ascension constructions (Choi 1988), and possessor agreement constructions (Cho 2003, Lee \& Cho 2003). These terms reflect the insight that the referent of the first NP inalienably possesses the referent of the second NP in (1). It has been tacitly assumed that there are some semantic relations between the referents of the same-case marked NPs. Some researchers advanced this insight and tried to classify the sequences of the same-case marked NPs into several subtypes. The studies mentioned above in this paragraph can be regarded as attempts to find an answer to the question related to the core properties P4 and P7.

As suggested above, it could be tempting to try and find a licensing condition for the sequences of same-case NPs (e.g., (1)) in the corresponding NP with a genitive-marked NP (e.g., (2)). The most widespread approach claims that the sequences of same-case NPs may be formed if the two consecutive same-case NPs are in a possessor-possessed relation. The approach advanced along this line of thinking is highly common in the derivational grammar framework. According to this approach, generally known as the genitive approach, additional nominative NP occurs via cyclic NP movement out of the subject NP with genitive specifiers. Since this approach is the most influential, it deserves detailed discussions in a separate Section 2.2.4.

While there can be no doubt that there exists a certain similarity between the multiple nominative constructions and the corresponding sentence with subject with a genitive NP, there are many other conceptual or distributional differences between the two sentences (see Na \& Huck 1993 and Kim 2000, among others).

First, the two sentences manifest meaning differences, as Na \& Huck (1993: 190) pointed out. If this is true, in terms of the transformational grammar, the MNCs and the genitive constructions may not share the same D-structure, whatever it may be. This is the first and the most fundamental problem which the genitive approach faces.

Second, MNCs in which more than two nominative NPs occur do not have corresponding genitive sources, where the second NP is realized in genitive, as shown in (16). 
(16) John-i chinkwu-ka/*-uy apeci-ka pwuca-i-ta.

John-NOM friend-NOM ${ }^{*}$-GEN father-NOM be.rich-PRES-DECL

'The father of John's friend is rich.'

Third, while the genitive approach might seem to be plausible at least for some MNCs, there are other MNCs which have no acceptable genitive source ( $\mathrm{Na} \&$ Huck 1993:190). As the examples in (17) show, all the MNCs, where the two consecutive NPs stand in a class-membership, an object-quantity, a space-object, or a conventional relation, are systematically ungrammatical.
a. pihayngki-ka/ ${ }^{*}$-uy $\quad 777-\mathbf{i} \quad k h u-t a$. airplane-NOM/*-GEN 777-NOM be.big-DECL
'It is as for airplanes that 777 is big.' (class-membership relation)
b. mal-i $/^{*}-u y \quad$ twu mali-ka talli-n-ta.
horse-NOM/*-GEN two head-NOM run-PRES-DECL
'Two heads of horses are running.'
(object-quantity relation)
c. thomatho-ka/ ${ }^{*}$-uy pelley-ka tulkkulh-nun-ta.
tomato-NOM $/{ }^{*}$-GEN worm-NOM be.infested-PRES-DECL
'Tomatos are infested with worms.' (space-object relation)
d. catongcha-ka/ ${ }^{*}-u y[$ isangha-n naymsay]-ka na-n-ta.

car-NOM $/{ }^{*}$-GEN be.strange-REL smell-NOM be.emitted-PRES-DECL
'A strange smell is emitted from the car.' (conventional relation)

Fourth, in a variety of cases a genitive is not readily convertible into a nominative NP (cf. Na \& Huck 1993: 191).

Fifth, some multiple nominative constructions have a proper noun NP in the position immediately preceding the main predicate. The last two points can be seen in example (18), which shows that the first NP in (18) may not be a possessor occurring in the specifier position of the corresponding NP structure.
(18) $\operatorname{san}-\mathbf{i} /{ }^{*}-u y$
selaksan-i
alumtap-ta.
mountain-NOM/-GEN Mt. Seorak-NOM be.beautiful-DECL
'As for mountains, Mt. Seorak is beautiful.'

To sum up, it is safe to draw the conclusion that, based on the semantic and distributional differences, multiple nominative constructions are constructions which may not be derived from the corresponding genitive sources. 


\section{A typology of multiple case marking constructions}

It goes back to Yang (1972), to my knowledge, to try to find the generative source of the sequences of same-case NPs in some semantic relationships between two consecutive nominative NPs. He argues that the 'macro-micro relation' is one of the generative sources, refuting the genitive view. ${ }^{7}$ This relation refers to a relation where an NP is conceptually divided into the whole NP itself and a subpart of it. The NP which corresponds to the former is referred to as a macro$\mathrm{NP}$, while that corresponding to the latter is referred to as a micro-NP. Yang (1972: 42ff.) classifies this macro-micro relation into 5 subtypes on the basis of their semantic contents: (i) whole-part, (ii) class-member, (ii) type-token, (iii) total-quantity, and finally (v) affected-affector. ${ }^{8}$

The licensing issue has been tackled again by Na \& Huck (1993). They proposed that two consecutive nominative case-marked NPs need to be in a certain semantic relation, called 'thematic subordination': $\mathrm{X}$ is 'thematically subordinate' to an entity Y iff Y's having the properties that it does entails that $\mathrm{X}$ has the properties that it does. The view in Na \& Huck (1993) has been adopted in many subsequent works in Korean linguistics (see Kim 2000, 2001, and Kim, Sells \& Yang 2007, among others). Na \& Huck (1993: 195) classify these thematic subordination relations into five subtypes: (i) part-whole relation (e. g., cover-book, morning-day, eye-person, etc.), (ii) qualitative relation (e. g., usetool, length-pants, height-woman, etc.), (iii) conventional relation (e.g., car-man, picture-woman, dog-girl, etc.), (iv) conversive relation (e.g., parent-child, masterservant, employer-employee, etc.), and (v) taxonomic relation (e. g., apple-fruit, oaktree, chair-furniture, etc.).

The part-whole relation and the taxonomic relation in Na \& Huck (1993) roughly correspond to the whole-part and the class-member relation in Yang (1972), respectively. The other three relations - qualitative, conventional, and conversive are newly proposed.

7 For other generative sources of the multiplication of case markers, Yang (1972: 159 \& 195) added two groups of verbs. One group includes verbs of self-judgment (e. g., siphta (to be desirous of), cohta (to be fond of), kipputa (to be glad), masissta (to be tasty), etc.) and verbs of semi-self-judgment (e. g. philyohata (to be necessary), chwungpunhata (to be enough), kanunghata (to be possible), swipta (to be easy), etc.). The other group Yang (1972:175) adds is verbs of existence (issta (to exist), epsta (not to exist), manhta (to exist a lot), and cekta (to barely exist)). The first group may well be regarded as psych-verbs.

8 According to Yang (1972:45), the affected-affector macro-micro relation is a 'solidarity' relation and some sort of natural pairing, e. g., kinship, teacher-student, society-individual, etc. We do not assume this relation as an independent class, but regard it as an instance of conversive relation. 
Such terms as whole-part, (inalienable/alienable) possessor-possessum, kinship, thing-property, locative-theme, etc. have sometimes been adopted in the literature (e.g., Choe 1987, Choi 1988, Youn 1990, Gerdts 1991/2000, Whitman 1991/2000, Kim 1996, Yoon 1997, Koh 1999, Moon 2000, Hong 2001, Lee 2008, etc.), and used to name the whole constructions at the same time (see Koh 1999, Hong 2001, Lee 2008, Choi 2008: 902 for a critical survey). At least three pieces of desiderata of this tradition may be alluded to.

First of all, the definitions of each term are not clear at all. For example, the whole-part relation is interchangeably used with the inalienable possessorpossessum relation in many works. As will be discussed below in detail, however, the inalienable possessor-possessum relation is only a subtype of six subtypes of the meronymic relation, and not all subtypes of the whole-part relation share the same properties with the inalienable possessor-possessum relation. This is one of the major sources of confusion found in many of the previous studies.

Another point of desiderata can be found in the sentences like (19), which Yang (1972: 43) regarded as an example of a part-whole relation. Such examples are problematic simply because of the fact that sayk (color) is not a part of mucikay (rainbow).

(19) ce mucikay-ka sayk-i kop-ta.

that rainbow-NOM color-NOM be.pretty-DECL

'That rainbow's color is pretty.'

A third piece of desiderata of the previous works is their incompleteness of classification. As will be clear soon, there are many other semantic relations which are responsible for multiplication of same-case NPs in Korean, but have unduly received little attention.

To remedy these desiderata, we start our discussion by advancing some important achievements of mereology and taking into consideration some data, which have, relatively speaking, been less frequently discussed in the literature.

\subsection{Meronymic relations}

Whole-part relations or meronomies gave rise to a wide range of studies in linguistics, psychology, philosophy and artificial intelligence (Cruse 1986, Iris et al. 1988 and Winston et al. 1987). Based on psycholinguistic experiments and the way in which the parts contribute to the structure of the wholes, Winston et al. (1987) determined six types of part-whole relations: (i) component-integral ob- 
ject, (ii) member-collection, (iii) portion-mass, (iv) stuff-object, (v) feature-activity, and (vi) place-area. Only the first relation has been previously discussed in the context of MCCs. We adopt the definition of the six types of meronymic relations in Winston et al. (1987), as summarized in Table 1. We argue that all six types should be assumed for licensing of the sequences of same-case NPs.

\begin{tabular}{|c|c|c|c|c|}
\hline Relation & Examples & Functional & Homeomerous & Separable \\
\hline integral-obj--component & $\begin{array}{c}\text { cup-handle } \\
\text { punchline-joke }\end{array}$ & - & - & + \\
\hline collection-member & $\begin{array}{l}\text { forest-tree } \\
\text { deck-card }\end{array}$ & - & - & + \\
\hline mass-portion & $\begin{array}{l}\text { pie-slice } \\
\text { salt-grain }\end{array}$ & - & + & + \\
\hline object-stuff & $\begin{array}{c}\text { martini-gin } \\
\text { bike-steel }\end{array}$ & - & - & - \\
\hline activity-feature & $\begin{array}{l}\text { shopping-paying } \\
\text { adolescence-dating }\end{array}$ & + & - & - \\
\hline area-place & $\begin{array}{c}\text { Florida-Everglades } \\
\text { desert-oasis }\end{array}$ & - & + & - \\
\hline
\end{tabular}

1. Functional (+)/Nonfunctional (-): Parts are/are not in a specific spatial/temporal position with respect to each other, which supports their functional role with respect to the whole.

2. Homeomerous (+)/Nonhomeomerous (-): Parts are similar/dissimilar to each other and to the whole to which they belong.

3. Separable $(+) /$ Inseparable (-): Parts can/cannot be physically disconnected, in principle, from the whole to which they are connected.

Table 1: Six types of meronymic relations: Winston et al. (1987: 421)

TyPe 1: InTEGRAL OBJECT-COMPONENT. The integral object-component relation is a relation between components and the objects to which they belong. Integral objects have a structure; their components are separable and have a functional relation with their wholes (e.g., elephant-nose, person-leg, bike-pedal, tree-bark, opera-aria, cup-handle, car-wheel, person-hand, person-hair, etc.). This relation roughly corresponds to the whole-part relation in Yang (1972), the part-whole relation in $\mathrm{Na} \&$ Huck (1993), and the inalienable possessive specifier relation of Park (2001). This relation is attested in the pairs of two consecutive NPs found in MNCs (20a) and MACs (20b).

(20) a. thokki-ka kwi-ka kil-ta.

rabbit-NOM ear-NOM be.long-DECL

'The ears of rabbits are long.' 


\section{b. Hans-ka thokki-lul kwi-lul cap-ass-ta.}

Hans-NOM rabbit-ACC ear-ACC grab-PAST-DECL

'Hans grabbed the ears of rabbits.'

As Winston et al. (1987) notes, pieces of objects are distinct from their components, and pieces belong to a different family of meronymic relations that we call mass-portion relation (see Type 3: Mass-portion below). Unlike components, pieces lack a determinate functional relation to their wholes, and typically have arbitrary boundaries, as Cruse (1986: 157ff.) notes.

Type 2: Collection-member. The collection-member relation represents membership in a collection. Members are parts, but they cannot be separated from their collections and do not play any functional role with respect to their whole (e. g., fleet-ship, army-soldier, faculty-professor, forest-tree, deck-card, etc.). Membership in a collection is determined on the basis of spatial proximity (e. g., to be part of a forest, a tree must be spatially close to the other trees) or by social connection (e. g., groups). This relation is also attested in the pairs of two consecutive NPs found in MNCs (21a) and MACs (21b).

a. $i$ hamtay-ka camswuham-i manh-ta.

this fleet-NOM submarine-NOM be.plenty-DECL

'There are plenty of submarines in this fleet.'

b. cekkwun- $i$ i hamtay-lul camswuham-ul paksalnay-ass-ta. enemy-NOM the fleet-ACC submarine-ACC destroy-PAST-DECL 'The enemy destroyed the submarines of this fleet.'

Collection must be distinguished from classes. The class-membership relation (see Type 7: Class-membership below) is not a meronymic relation, because it is not expressed by 'part,' but by 'is.'

TyPe 3: MAss-PORTION. The mass-portion relation captures the relations between portions and masses, extensive objects, and physical dimensions. The parts are separable and similar to each other and to the wholes which they comprise, and do not play any functional role with respect to their whole (e. g., pie-slice, kilometer-meter, salt-grain of salt, cake-piece, etc.). This relation is also attested in the pairs of two consecutive NPs found in MNCs (22a) and MACs (22b).

a. sokum-i alkayngi-ka kwulk-ta. salt-NOM grain-NOM be.thick-DECL 'The grains of (this) salt are thick.' 
b. Hans-ka sokum-ul alkayngi-lul noki-ess-ta. Hans-NOM salt-ACC grain-ACC melt-PAST-DECL 'Hans melted the grains of (this) salt.'

Type 4: ОвJест-Stuff. The object-stuff category encodes the relations between an object and the stuff of which it is partly or entirely made. The parts are not similar to the wholes that they comprise, cannot be separated from the whole, and have no functional role (e.g., car-steel sheet, desk-wood, bike-steel, etc.). This relation is also attested in the pairs of two consecutive NPs found in MNCs (23a) and MACs (23b).
a. KIA cha-ka kangphan-i twukkep-ta.
KIA car-NOM steel sheet-NOM be.thick-DECL 'The steel sheet of KIA cars is thick.'
b. Hans-ka KIA cha-lul kangphan-ul cohaha-n-ta. Hans-NOM KIA car-ACC steel sheet-ACC like-PRES-DECL 'Hans likes the steel sheet of KIA cars.'

Type 5: Feature-Activity. The feature-activity relation captures the semantic links within features or phases of various activities or processes. The parts have a functional role, but they are not similar or separable from the whole (e.g., golf-putting, eating-swallowing, shopping-paying and eating-chewing, etc.). This relation is also attested in the pairs of two consecutive NPs found in MNCs (24a) and MACs (24b).

a. kolphu-ka phething-i elyep-ta. golf-NOM putting-NOM be.difficult-DECL

'As as as the game of golf is concerned, the putting is difficult.'

b. Hans-ka kolphu-lul phething-ul cohaha-n-ta.

Hans-NOM golf-ACC putting-ACC like-PRES-DECL

'What Hans likes about golf is the putting.'

Type 6: AreA-PlAce. The area-place relation captures the relation between areas and special places and locations within them. The parts are similar to their wholes, but they are not separable from them (e. g., Korea-Seoul, Florida-Everglades, desert-oasis, etc.). This relation is also attested in the pairs of two consecutive NPs found in MNCs (25a) and MACs (25b).
a. California-ka Silicon Valley-ka ttattusha-ta.
California-NOM Silicon Valley-NOM be.warm-PAST-DECL
'It is warm in California's Silicon Valley.' 
b. Hans-ka California-lul Silicon Valley-lul pangmunha-ess-ta. Hans-NOM California-ACC Silicon Valley-ACC visit-PAST-DECL 'Hans visited Silicon Valley in California.'

So far, we have introduced 6 types of whole-part relations. We have argued that each type functions as a licensing condition for multiplication of same-case NPs, showing that each type can be attested in the pairs of two consecutive NPs found in MNCs and MACs. It amounts to the claim that the meromymic relations are syntactically visible in MCCs in Korean. We will show 10 more nonmeronymic relations which are responsible for multiple case marking in Korean.

\subsection{Inclusion relations}

Type 7: Class-membership. Class-membership or hyponymy is not a part-whole relation, and is usually expressed in the frames, 'Xs are type of $Y$,' 'Xs are Ys,' ' $\mathrm{X}$ is a kind of Y', and 'X is a Y' (Cruse 1986: 89, Lyons 1977: 292, Miller \& Johnson-Laird 1976: 241). Class inclusion and meronymy (especially, collection-membership) are clearly distinguished when expressed by 'kind of' and 'part of.' (e. g., flower-rose, airplane-777, dog-German shepherd, fruit-apple, tree-oak, furniture-chair, tool-saw, bird-sparrow, clothes-shirt, games-soccer, etc.). ${ }^{9}$

This relation corresponds to the class-member relation in Yang (1972) and Park (2001), and the taxonomic relation in $\mathrm{Na} \&$ Huck (1993). This relation is one of the major sources of the pairs of two consecutive NPs found in MNCs (26a) and MACs (26b).
a. pihayngki-ka eyepesu-ka khu-ta. airplane-NOM Airbus-NOM be.big-DECL
'The Airbus airplane is big.'
b. Hans-ka pihayngki-lul eyepesu-lul tha-ass-ta.
Hans-NOM airplane-ACC Airbus-ACC take-PAST-DECL
'John took the Airbus airplane.'

\footnotetext{
9 They are sometimes difficult to distinguish in the case of activities and abstract nouns. They can be ambiguous as to whether they are to be taken as expressing class inclusion or meronymy (Lyons 1977: 314-316), as can be seen in (i).
}
(i) a. Frying is part of/a type of cooking.
b. Honesty is part of/a type of virtue. 
This relation properly includes the type-token relation in Yang (1972), since 'rising sun' is a kind of 'sun' in (27).

(27) hay-ka [ttu-nun hay]-ka mesiss-ta.

sun-NOM rise-REL sun-NOM be.spectacular-DECL

'As for the sun, the rising sun is spectacular.'

Free relatives with bound nouns like kos (place) and pun (honored person) may be regarded as an example of class-membership, as can be seen in (28). Given that the relative pronoun must be co-indexed with the preceding noun, 'the restaurant whose foods are delicious' is a kind of 'restaurant' in (28).
a. siktang-i
*(masiss-nun) kos-i
cek-ta. restaurant-NOM be.delicious-REL place-NOM be.rare-DECL 'Restaurants whose foods are delicious are rare.'
b. kyoswu-ka *(yumyengha-n) pun-i manh-ta. professor-NOM be.famous-REL person-NOM be.many-DECL 'There are many professors who are famous.'

Type 8: Овјест-Aтtachment. Pairs such as ear-earring, chimney-TV antenna, and fishing line-hook do not express a part-whole relation, since the latter may be attached to, but not parts of, the former. This relation, which we call objectattachment relation, might be confused with meronymy since the relation paraphrased by 'to be attached to' can be also observed in whole-part relations: for example, earrings are attached to ears and fingers are attached to hands. Fingers are attached to hands, but they are also parts of hands; while earrings are attached to ears, but are not parts of ears (cf. Cruse 1979).

This relation is also attested in the pairs of two consecutive NPs found in MNCs (29a) and MACs (29b).

(29) a. kwi-ka kwikoli-ka nemu khu-ta. ear-NOM earring-NOM too be.big-DECL

'The earrings of the ears are too big.'

b. Hans-ka kwi-lul kwikoli-lul cap-ass-ta.

Hans-NOM ear-ACC earring-ACC grasp-PAST-DECL

'John grasped the earrings of the ears.' 


\subsection{Quality-quantity relations}

Type 9: ОвJест-QUALITy. The object-quality relation captures a relation between an object and its typical property. The objects may or may not form a structure, their properties have a characterizing function (e. g., tool-use, pants-length, personheight, eyes-color, skin-texture, room-temperature, food-taste, hair-shine, etc.). The object-quality relation is frequently attested in the sequences of the two consecutive same-case NPs, as shown in (30).
a. paci-ka kili-ka ccalp-ta.
pants-NOM length-NOM be.short-DECL
'The length of the pants is short.'
b. Hans-ka paci-lul kili-lul calu-ess-ta.
Hans-NOM pants-ACC length-ACC cut-PAST-DECL
'Hans cut the length of the pants.'

Type 10: ОвJECT-QuANTITY. The object-quantity relation captures a relation between an object and its floated quantifiers (e. g., student-number CL, horses-number $C L$, water-number $C L$, car-number $C L$, apple-number $C L$, etc.). The sentences in (31) are sometimes called floating quantifier constructions (FQCs). They clearly show that they are formed on the basis of this object-quantity relation, and contain consecutive NPs sharing nominative case ((31)a) or accusative case ((31)b).
a. haksayng-i twu myeng-i o-ass-ta. student-NOM two person-NOM come-PAST-DECL 'Two of the students came.'
b. Fohn-i haksayng-ul twu myeng-ul ponay-ess-ta. John-NOM student-ACC two person-ACC send-PAST-DECL 'John sent two of the students.'

In Sections 3.2 and 3.3, we introduced 4 more types of semantic relations which are different from meronymic relations. Type 7 (class-membership relation) and Type 8 (object-attachment relation) are grouped into inclusion relation, and Type 9 (object-quality relation) and Type 10 (object-quantity relation) are grouped into quality-quantity relation. We argued that each of these 4 types functions as a licensing condition for multiplication of same-case NPs, showing that each type can be attested in the pairs of two consecutive NPs found in MNCs and MACs. We will show 6 more relations which are responsible for multiple case marking in Korean. 


\subsection{Spatio-temporal relations}

Type 11: Space-овject. The space-object relation represents a relation between an object and the space in which it is placed (e. g., container-crack, tomato-worm, beach-girl; city-weather, kids-illness, etc.). This relation captures the relationship between two NPs found in the locative type of Park (2001). This relation, however, is not attested in MACs as shown in (32b), but only in the sequences of the two consecutive nominative NPs, as can be seen in (32a).
a. ku haypyen-i miin-tul-i katukha-ta. that beach-NOM sexy girl-PL-NOM be.crowed-DECL 'The beach is crowded with sexy girls.'
b. "na-nun ku haypyen-ul miin-tul-ul cohaha-n-ta. I-TOP that beach-ACC sexy girl-PL-ACC like-PRES-DECL

Type 12: Tiмe-овJест. The time-object relation captures a relation between an object and the time in which it occurs (e. g., summer-beer, autumn-weather, nowadayscamera, spring-flowers, yesterday-body, tomorrow-kids, that time-cinema, etc.). Sentences like (32a) are sometimes called adjunct type DNCs (cf. Kim, Sells \& Yang 2007 among others). Interestingly enough, this relation is not attested in MACs as shown in (33b), but only in MNCs, as can be seen in (33a).
a. yelum-i maykcwu-ka masiss-ta.
summer-NOM beer-PL-NOM be.tasty-DECL
'Beers of summer are tasty.'
b. "na-nun yelum-ul maykcwu-lul cohaha-n-ta.
I-TOP summer-ACC beer-PL-ACC like-PRES-DECL

\subsection{Predication relations}

Type 13: Possessor-OBJect. The possessor-object relation, in general, is an asymmetric relationship between two constituents, the referent of one of which (= the possessor) possesses the referent of the other (= the object). X and Y may enter into a possessor-object relation, if their relations may be characterized by such predicates as have, own, and rules over. This relation is not attested in MACs, but only in MNCs, as can be seen in (34).

(34) a. ku yeca-ka kapang-i mesiss-ta. that lady-NOM bag-PL-NOM be.fashionable-DECL 'The bag of that lady is fashionable.' 
b. "na-nun ku yeca-lul kapang-ul cohaha-n-ta.

I-TOP that lady-ACC bag-PL-ACC like-PRES-DECL

Alienable and inalienable possession are commonly distinguished. We understand only the alienable possession under Type 13 (possessor-object relation). The inalienable possession is a proper portion of Type 1 (integral object-component relation).

Type 14: Conventional Relation. The conventional relation captures relations in which some entity $\mathrm{X}$ is related to some individual $\mathrm{Y}$ by virtue of convention, rather than as a consequence of their inherent properties. Following Cruse (1986) and $\mathrm{Na} \&$ Huck (1993), we'll call these relationships conventional (e. g., mancar, woman-picture, car-smell, tiger-area of movement, girl-dog, boy-hat, bird-nest, animal-territory, person-clothes, etc.). There are in principle a variety of conventional relations into which $\mathrm{X}$ and $\mathrm{Y}$ may enter if a conventional relation holds between $\mathrm{X}$ and $\mathrm{Y}$, and these relations may be more accurately characterized by a variety of predicates other than have (cf. Na \& Huck 1993: 197). ${ }^{10}$
a. the car that the man drives
b. the clothes that the boy is modeling
c. the house that the architect designed

This relation is not attested in MACs, but only in MNCs, as can be seen in (36).
a. tokil-i
catongcha-ka thunthunha-ta.
Germany-NOM car-NOM be.solid-PRES-DECL
'The cars manufactured in Germany are solid.'
b. "na-nun tokil-lul catongcha-lul cohaha-n-ta.
I-TOP Germany-ACC car-ACC like-PRES-DECL

Type 15: OBject-predicAtion. The object-predication relation captures an asymmetric relation between two consecutive NPs; the referent of the one is construed to be agent or theme argument of the other (e. g., person-complaint, father-love, bomb-explosion, car-acceleration, ship-voyage, etc.). The NPs expressing predication are typically Sino-Korean verbal nouns as pulphyeng (complaint) in (37), but

\footnotetext{
${ }^{10}$ According to Na \& Huck (1993), conventional relations differ from meronomic and qualitative relations in at least one respect which has important linguistic consequences. If $\mathrm{X}$ is thematically subordinate to $\mathrm{Y}$, and if $\mathrm{X}$ and $\mathrm{Y}$ are in a meronomic relation (similarly for qualitative relations), then there is only one possible relation into which $\mathrm{X}$ and $\mathrm{Y}$ can enter. In English, this relation is characterized by the predicate have, so that a complex NP may be formed such that ' $\mathrm{X}$ which (a, the) $\mathrm{Y}$ has' is grammatical.
} 
they can be gerunds formed by attaching a derivational suffix $-k i$ or $-u m$ as $i l k-k i$ (reading) in (38). ${ }^{11}$ The two NPs involved in an object-predication relation cannot occur in the context of MACs (37b), but only in MNCs, as shown in (37a).
a. ttal-i pulphyeng-i taytanha-ta. daughter-NOM complaint-NOM be.plenty-DECL 'The complaints of (my) daughter are plenty.'
b. "na-nun ttal-ul pulphyeng-ul miwuyha-n-ta. I-TOP daughter-ACC complaint-ACC hate-PRES-DECL

When a gerund is a predication noun, the case marking pattern is somewhat different from that of the sentences in which a Sino-Korean verbal noun is used as a predication noun. While the left-most NP may be marked either by nominative or by accusative case in the context of MNCs, only accusative marking is allowed in the context of MACs, as can be seen in (38).
a. $i \quad$ chayk-i/-ul ilk-ki-ka elyep-ta.
this book-NOM/-ACC read-NMZ-NOM be.difficult-DECL
'This book is difficult to read.'
b. Hans-ka $i$ chayk-*i/ul ilk-ki-lul silheha-n-ta. Hans-NOM this book-*NOM/-ACC read-NMZ-ACC hate-PRES-DECL 'Hans hates to read this book.'

Nominative marking in (38a) and accusative marking in (38b) are not surprising, but accusative marking in (38a) needs an explanation. Given that a gerund like $i l k-k i$ (reading) has both a nominal and a verbal property at the same time, it is reasonable to assume that the accusative-marked [NP $i$ chayk-ul] (this book) is in the complement position inside the VP headed by $i l k$ - (to read): $\left[_{\mathrm{NP}}\left[\mathrm{VP}\left[_{\mathrm{NP}} i\right.\right.\right.$ chayk-ul] [V $\left.i l k-]]\left[\mathrm{N}^{-}-k i\right]\right]$.

Type 16: Conversive Relation. Following Na \& Huck (1993), we define the conversive relation as a (roughly symmetric) relation in which the entities denoted by the first nouns are in the relevant cases construed to be in institutional hierarchies to the entities denoted by the second nouns with which they are paired (e. g., parent-child, master-servant, employer-employee, husband-wife, doctor-patient, hostparasite, etc.). The kinship relations, the social relations, and the so-called affector-

11 The object-predication relation is a major source of multiple same-case marking in verbal noun constructions, in which the functional verbs hata (to do) and toyta (to become) are used to form active and passive sentences, respectively (see Ryu 1993 for details). 
affected relation in Yang (1972) are subsumed by the conversive relation. This relation is not attested in MACs, but only in MNCs, as can be seen in (39).

a. ku uysa-ka hwanca-ka manh-ta.

that doctor-NOM patient-NOM be.plenty-DECL

'The patients of that doctor are plenty.'

b. "na-nun ku uysa-lul hwanca-lul cohaha-n-ta.

I-TOP that doctor-ACC patient-ACC like-PRES-DECL

So far, we have introduced 6 semantic relations which can be observed in the context of MNCs, but not in MACs. As a whole, we have identified 16 types of the sequences of same-case NPs in Korean, as summarized in Table 2.

\begin{tabular}{|c|c|c|c|}
\hline Proposed type of MCCs & Yang (1972) & Na \& Huck (1993) & $\begin{array}{l}\text { Other terms used } \\
\text { elsewhere in the literature }\end{array}$ \\
\hline Type 1: integral obj.-component & whole-part & I meronomic rel. & I inalienable possession con. \\
\hline Type 2: collection-member & $\times$ & $\times$ & $\times$ \\
\hline Type 3: mass-portion & $\times$ & $\times$ & $\times$ \\
\hline Type 4: object-stuff & 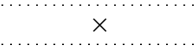 & $\ddot{x}$ & $\begin{array}{l}\cdots \\
\times\end{array}$ \\
\hline Type 5: activity-feature & $\times$ & $\times$ & $\times$ \\
\hline Type 6: area-place & $\times$ & $\times$ & $\times$ \\
\hline Type 7: class-membership & $\begin{array}{l}\text { class-member } \\
\text { type-token }\end{array}$ & taxonomic rel. & $\begin{array}{l}\text { NP-split con. } \\
\text { type-token }\end{array}$ \\
\hline Type 8: object-attachment & $\times$ & $i^{\prime}$ & ${ }^{\times}$ \\
\hline Type 9: object-quality & $\times$ & qualitative & thing-property \\
\hline Type 10: object-quantity & total-quantity & $\times$ & floating quantifier con. \\
\hline Type 11: space-object & $\times$ & $\times$ & locative-theme \\
\hline Type 12: time-object & $\times$ & $\times$ & adjunct focus con. \\
\hline Type 13: possessor-object & $\times$ & $x$ & alienable possession \\
\hline Type 14: conventional relation & $\times$ & conventional & $\times$ \\
\hline Type 15: object-predication & $\times$ & $\times$ & $\begin{array}{l}\text { tough con. } \\
\text { light verb con. }\end{array}$ \\
\hline Type 16: conversive relation & affected-affector & conversive & $\begin{array}{l}\text { kinship, solidarity, } \\
\text { or social relation }\end{array}$ \\
\hline
\end{tabular}

1. rel. and con. is an abbreviation for 'relation' and 'constructions', respectively.

2. The symbol $\times$ refers to 'not mentioned.'

Table 2: A comparison of types of multiple case marking constructions 


\section{The formation of multiple case marking constructions}

\subsection{The 16 semantic relations as licensing conditions}

We have identified 16 semantic relations which may hold between the two consecutive identical case marked NPs in MCCs. We have shown that 10 out of 16 semantic relations (Type 1 to Type 10) are attested in both MNCs and MACs. The other 6 semantic relations (Type 11 to Type 16) are attested in MNCs, but not in MACs. It follows from what has been discussed that at least the 16 semantic relations constitute the backbone of the formation of a pair of the same-case marked NPs.

In Section 1, we showed that the NP immediately preceding the intransitive predicate is an argument. This argument is the right-most NP of the sequences of the identical case-marked NPs, regardless of the number of the NPs occurring in the sequence. All additional NPs preceding the argument NP are nonargument.

DCCs are exactly the constructions in which two consecutive same-case marked NPs occur, one of which is not subcategorized for by the predicate. We argue that MCCs are formed by dextrosinistrally sequencing the pairs of the samecase marked NPs of same or different type. In other words, the 16 semantic relations constitute a licensing condition for forming a pair of the same-case marked NPs, and consequently a licensing condition for forming MCCs.

Let me illustrate the process of formation of MCCs step by step. We made it clear that the most basic clause of MCCs is DCCs in which only two consecutive same-case marked NPs occur. For example, the MCCs in (40b)-(40d) are formed on the basis of the clause (40a).

a. $\left[_{\mathrm{NP}_{1}}\right.$ thel-i] kil-ta.

fur-NOM be.long-DECL

'The fur is long.'

b. $\left[\mathrm{NP}_{2} k k u t h-\mathbf{i}\right]\left[\mathrm{NP}_{1}\right.$ thel-i] kil-ta. top-NOM fur-NOM be.long-DECL

'The fur of the top is long.'

c. $\left[\mathrm{NP}_{3} k w i-\mathbf{k a}\right]\left[\mathrm{NP}_{2} k k u t h-\mathbf{i}\right]\left[{ }_{\mathrm{NP}_{1}}\right.$ thel-i] $k i l-t a$. ear-NOM top-NOM fur-NOM be.long-DECL

'The fur of the top of the ears is long.' 


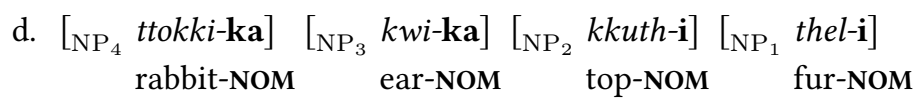
kil-ta.

be.long-DECL

'The fur of the top of the ears of the rabbit is long.'

The $\mathrm{NP}_{2}$ is licensed in (40b), since it stands in an object-attachment relation (Type 8) to $\mathrm{NP}_{1}$. The $\mathrm{NP}_{3}$ is licensed in (40b), since it stands in an area-place relation (Type 6) to $\mathrm{NP}_{2}$. The $\mathrm{NP}_{4}$ is licensed in (40b), since it stands in an integral objectcomponent relation (Type 1) to $\mathrm{NP}_{3}$.

More complicated clauses can be explained according to our proposal. Let us examine the sentence (7), repeated here in (41b) for ease of presentation.

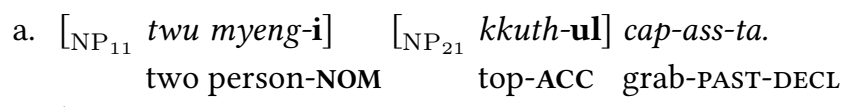

'Two persons grabbed the top.'

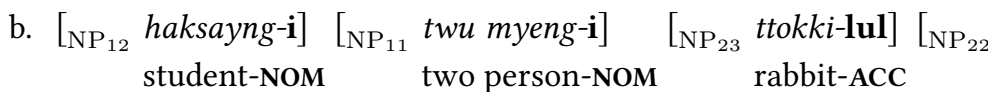
$k u y$-lul $]\left[\mathrm{NP}_{21}\right.$ kkuth-ul] cap-ass-ta.

ear-ACC top-ACC grab-PAST-DECL

'Two students grabbed the top of the ears of rabbits.'

In (41), the predicate cap- (to grab) is a transitive verb, subcategorizing $\mathrm{NP}_{11}$ and $\mathrm{NP}_{21}$. The clause (41b) is formed on the basis of the simplest clause (41a). $\mathrm{NP}_{12}$ is licensed in (41b), since it stands in an object-quantity relation (Type 10) to $\mathrm{NP}_{11}$. $\mathrm{NP}_{22}$ is licensed in (41b), since it stands in an area-place relation (Type 6) to $\mathrm{NP}_{21}$. $\mathrm{NP}_{23}$ is licensed in (41b), since it stands in an integral object-component relation (Type 1) to $\mathrm{NP}_{22}$.

The licensing condition proposed here can explain the formation of MCCs like (9a), but also the ungrammaticality of sequences like (9b). For the purpose of presentation, we repeat the relevant examples in (42).

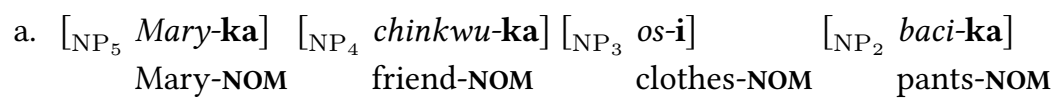

$$
\begin{aligned}
& \text { [ } \mathrm{NP}_{1} \text { thong-i] khu-ta. } \\
& \text { pant legs-NOM be.wide-DECL } \\
& \text { 'The pant legs of pants of clothes of friends of Mary are wide.' }
\end{aligned}
$$




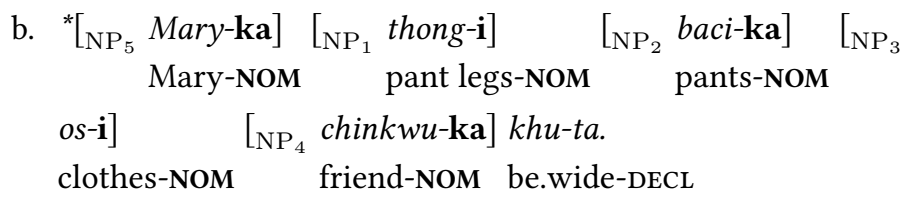

In (42a), ${ }_{\mathrm{NP}_{5}}$ Mary-ka] stands in a conversive relation (Type 16) to $\left[_{\mathrm{NP}_{4}}\right.$ chinkwu$\mathbf{k a}$, which in turn stands in a possession-object relation (Type 13) to $\left[\mathrm{NP}_{3}\right.$ os-i], which in turn in a class-membership relation (Type 7) to $\left[\mathrm{NP}_{2}\right.$ baci-ka], which in turn stands in an object-quality relation (Type 9) to ${\left[\mathrm{NP}_{1}\right.}_{1}$ thong-i]. The $\mathrm{NP}_{1}$ is subcategorized for by the predicate $k h u$ - (to be big) and all other NPs are licensed by the licensing condition proposed here.

However, the example (42b) is ungrammatical, although the same NPs occur as in the grammatical counterpart (42a). It should be noted that, unlike in (42a), $\left[\mathrm{NP}_{4}\right.$ chinkwu-ka] - i. e., not $\left[\mathrm{NP}_{1}\right.$ thong-i $]$ - is subcategorized for by the predicate in (42b). The ungrammaticality of (42b) can be explained in various ways: first of all, the second right-most $\mathrm{NP}\left[\mathrm{NP}_{3}\right.$ os-i] may not be licensed by any semantic relations. Second, although $\left[_{\mathrm{NP}_{5}}\right.$ Mary-ka] stands in a conversive relation (Type 16) to $\left[\mathrm{NP}_{4}\right.$ chinkwu-ka], there are many other NPs between them, which do not stand in a semantic relation to the latter. In other words, the example (42b) is ungrammatical, since $\mathrm{NP}_{5}$ and $\mathrm{NP}_{1}$ are not consecutive.

\subsection{Multiple case marking as case sharing}

The main idea being put forward in this paper is that the sequences of samecase NPs can be cyclically formed, if the immediately preceding NP stands in one of the 16 semantic relations to the right-most NP of the sequence. Therefore, the right-most NP of the sequence of same-case NPs is the starting point of the formation of the sequences of same-case NPs in Korean.

There are some pieces of evidence for the assumption that the right-most NP of an NP sequences functions as "conceptual head" and argument of the predicate. Let us examine the example (43) from Cho \& Lee (2003):
a. Mary-ka John-ul elkwul-ul ttayly-ess-ta. Mary-NOM John-ACC face-ACC hit-PAST-DECL 'Mary hit John's face.'
b. "Mary-ka fohn-ul elkwul-ul salanghay-ss-ta. Mary-NOM John-ACC face-ACC love-PAST-DECL 'Mary loved John's face.'


The sentence (43b) is ungrammatical, since the NP elkwul (face) violates the selectional requirement of the verb salanghata (to love). This example shows that the the right-most NP of an NP sequences is argument of the predicate.

The contrast between (44a) and (44b) further supports the view that the rightmost NP of an NP sequence is the argument selected by the predicate.
a. Vampire-ka fohn-ul phi-lul ppal-ass-ta

Vampire-NOM John-ACC blood-ACC suck-PAST-DECL

'A vampire sucked John's blood.'

(Type 1: Integrated object-component)

b. "Vampire-ka fohn-ul phi-lul masi-ess-ta

Vampire-NOM John-ACC blood-ACC drink-PAST-DECL

'A vampire drank John's blood.'

(Type 13: possessor-object)

The sentence (44b) is ungrammatical, since the verb masita (to drink) requires an NP having the feature [-integrated], whereas the verb ppalta (suck) selects an NP [+integrated] (examples from Cho \& Lee 2003). The NPs standing in a possessorobject relation cannot occur in multiple accusative marking contexts. So, (44b) is ungrammatical.

We argue in this section that the two consecutive NPs are identically casemarked via case sharing, if they stand in one of the 16 semantic relations. In this sense, licensing of NPs is morphosyntactically visible by the identical case. We can illustrate the mechanism of multiple case marking as follows:

(45) Multiple case marking as case sharing

a. Double case marking

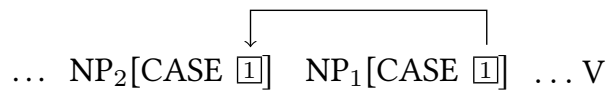

b. Multiple case marking

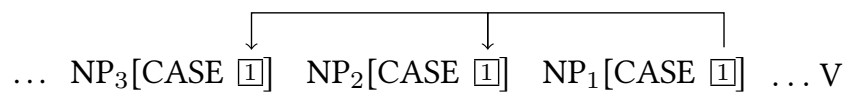

There are many pieces of evidence showing that the licensing of NPs is accompanied by the identical case. First of all, the active-passive alternation shows that the identical case should be shared between the NPs within the sequence. We have already illustrated this point in (7) and (8), which we repeat here in (46a) and (46b). 


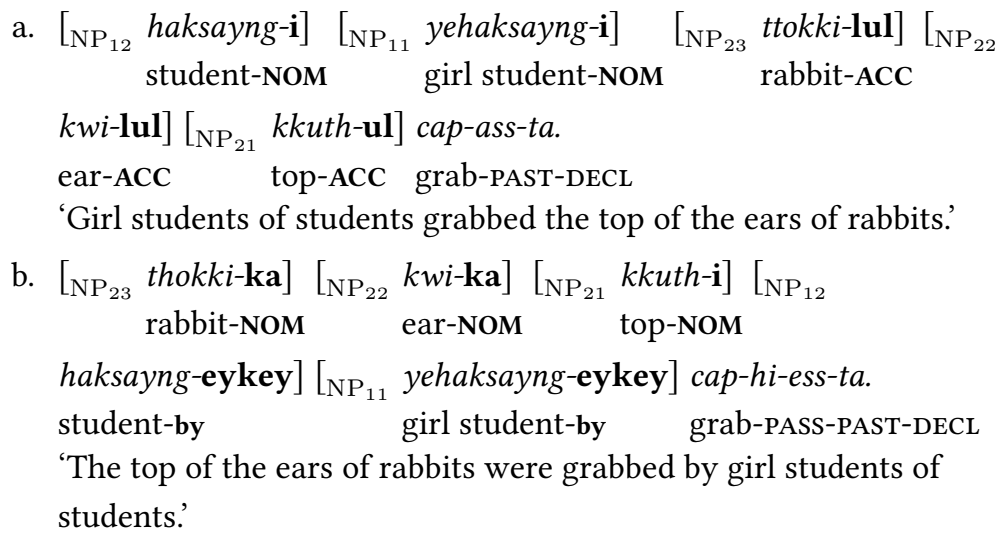

There are two sets of sequences of NPs marked with the same case in (46a); one set in the context of nominative case marking, and the other in the context of accusative case marking. By contrast, the former occurs in the context of agentive postposition marking - eykey in (46b), and the latter in the context of nominative case marking. ${ }^{12}$ The point to be noted here is that all the NPs in each sequence can be marked with the same-case marker.

${ }^{12}$ In Korean, the case markers on the case-agreeing nominal in some highly restricted set of MCCs alternate between nominative and accusative depending on voice. In addition to the passive sentence (46b), a more complicated passive sentence is possible in Korean, where the second and the third NP are alternatively marked with accusative case, as shown in (i). I thank Ik-Soo Kwon (p.c.) for drawing my attention to this phenomenon. Maling \& Kim (1992) and Cho \& Lee (2003) assume that the lexical passives of Korean do not always absorb accusative case. In particular, they assume that an indirect 'adversity' passive adds a benefactive/malefactive subject and assigns accusative case to its complements.

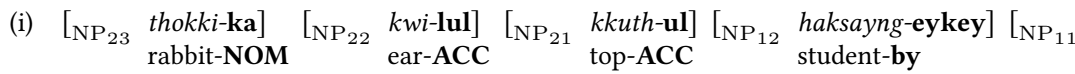
yehaksayng-eykey] cap-hi-ess-ta. girl student-by grab-PASS-PAST-DECL

'The top of the ears of rabbits were grabbed by girl students of students.'

Some technical details aside, Maling \& Kim (1992) and Cho \& Lee (2003) do not account for such sentences as in (i) in the same way as they do for passive sentences in general. Many researcher seem to agree that these sentences should be regarded as a special case, and they may not be seen as a counter-example against the general case-sharing proposal.

The peculiarity of such sentences as in (i) can be found in several points: First, this case marking pattern is not observed in the so-called phrasal passive, but only in the lexical passive. Second, some additional selectional restrictions such as [+animateness] are required for the left-most NP. Third, a transitive relation should hold between the NPs occurring within the sequence of NPs.

We speculate that some sort of theta-transfer (cf. Lee \& Cho 2003) is involved in the process of passivization. We further speculate that this peculiar case marking pattern occur only in the subtypes of meronymic relations (Type 1 to Type 6). Other types of MCCs do not show this peculiarity. The generalization would be as follows: Only the left-most NP of the sequence of NPs entering the 6 meronymic relations (Type 1 to Type 6) can be marked with nominative in passive voice, leaving all other NPs marked with accusative case, if a transitive relation holds between the NPs within the sequence. 
A second set of evidence comes from Yang's (1972) observation. Yang (1972: 51 ff.) observed that the macro-micro relations are not confined only to the nominative marker. This relation also holds true with other case markers. In our terms, NPs may be marked with the same case - be it with nominative, accusative or other semantic case markers - if they are licensed by the semantic relations.

a. John-ka ai-eykey chakha-n ai-eykey Bible-ul kaluchi-ess-ta. John-NOM child-DAT be.good-REL child-DAT Bible-ACC teach-PAST-DECL 'John taught the Bible to a child, a good child.' (class-membership)

b. Mary-ka cha-lo pemphe-lo cencwu-lul pat-ass-ta.

Mary-NOM car-INST bumper-INST pole-ACC hit-PAST-DECL 'Mary hit an electric pole with her car's bumper.' (integral objectcomponent)

c. $i \quad k a n g a r o o-k a$ nampankwu-eyse Australia-eyse this kangaroo-NOM Southern Hemisphere-SRC Australia-SRC o-ass-ta. come-PAST-DECL

'This kangaroo came from the Southern Hemisphere, from Australia.' (area-place)

d. Mary-ka caknyen-ey kaul-ey sicipka-ass-ta. Mary-NOM last year-TMP autumn-TMP marry-PAST-DECL 'Mary married last fall.'

(mass-portion)

e. saca-ka holangi-hanthey $t w u$ mali-hanthey ka-ass-ta. lion-NOM tiger-GOAL two heads-GOAL go-PAST-DECL 'A lion went to two heads of tigers.' (object-quantity)

f. Mary-ka cip-eyse pang-eyse kongpwuha-ess-ta.

Mary-NOM home-LOC room-LOC study-PAST-DECL

'Mary studied at home, in the room.' (integral object-component)

The examples in (47) show that the two consecutive NPs which enter into one of the 16 semantic relations are identically marked with semantic case markers such as dative, instrumental, source, temporal, goal, and locative case marker.

Concerning the core property P1, we argued in Section 1 that the simplest form of the psych-verb constructions in (10) and the copulative constructions in (11) is not an instance of MNCs, consequently not an instance of MCCs. This is not to say that these two constructions may not involve sequences of identical case-marked NPs, since it is possible to add an additional nominative NP to the 
position preceding to the first or the second NP. The examples in (48) are MCCs formed on the basis of these two constructions.

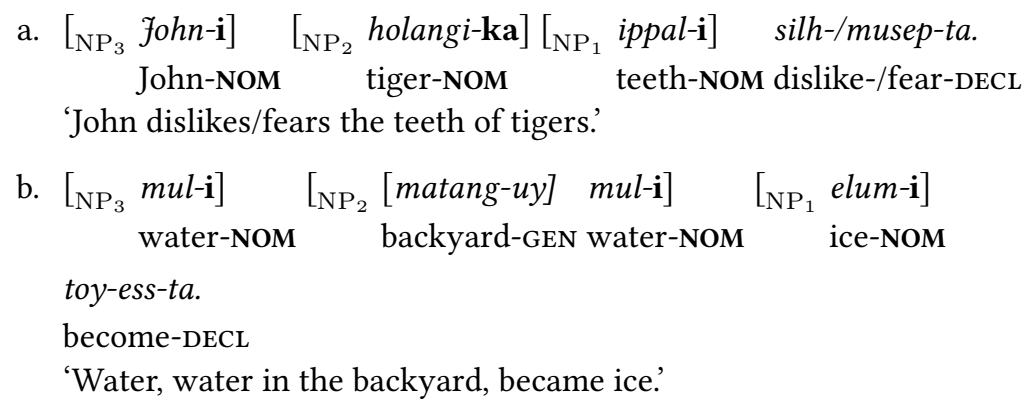

It should be noted that, while $\mathrm{NP}_{3}$ and $\mathrm{NP}_{1}$ are subcategorized for in (48a), $\mathrm{NP}_{2}$ and $\mathrm{NP}_{1}$ are subcategorized for by the predicate in (48b). The only nonargument $\mathrm{NP}$ in (48a) is $\mathrm{NP}_{2}$, which is licensed by Type 1 integral object-component relation holding between $\mathrm{NP}_{2}$ and $\mathrm{NP}_{1}$. In the same vein, the only nonargument $\mathrm{NP}$ in (48b) is $\mathrm{NP}_{3}$, which is licensed by Type 7 class-membership relation holding between $\mathrm{NP}_{1}$ and $\mathrm{NP}_{2}$. Thus, our proposal predicts that the two constructions can be MCCs, if more than three identical case-marked NPs occur.

\subsection{Multiple nominative vs. accusative marking}

It has been touched on from time to time but not explored in detail that multiple accusative marking is a little more constrained than multiple nominative marking (e. g., in Bak 1992, Lee 1994, Choi 2008 among others). In Section 3, we have shown that 10 out of 16 semantic relations (Type 1 to Type 10) are attested in both MNCs and MACs. The other 6 semantic relations (Type 11 to Type 16) are attested in MNCs, but not in MACs. The discussion in Section 3 enables us to answer the long-standing question as to in what respects the multiple nominative marking and the multiple accusative marking are alike and different from each other. If our discussion is correct, the answer is the generalization of the discussion in Section 3 which can be stated as follows:

(49) Multiple nominative vs. accusative marking

a. The nominative case of the right-most NP may be shared with an additional preceding consecutive NP, if the latter stands in one of the 16 semantic relations to the former (Type 1 to Type 16). 
b. The accusative case of the right-most NP may be shared with an additional preceding consecutive NP, if the latter stands in one of the first 10 semantic relations to the former (Type 1 to Type 10).

The semantic relations which do not license the sequence of accusative NPs are Type 11 (space-object), Type 12 (time-object), Type 13 (possessor-object), Type 14 (conventional relation), Type 15 (object-predication), and Type 16 (conversive relation). The set of the semantic relations in MACs is a proper subset of the semantic relations in MNCs. It turns out that there is no relation which occur in MACs, but not in MNCs.

\section{Conclusion}

The purpose of this paper was twofold. The first purpose was to argue that there are at least 16 types of sequences of same-case NPs in Korean. The second purpose was to answer the question of in what respects the multiple nominative marking and the multiple accusative marking are alike and different from each other.

We examined comprehensive data including some less frequently discussed examples, and identify 16 semantic relations found in the pairs of identical casemarked NPs. After showing that all these types are attested in MCCs, we argue that MCCs are formed by dextrosinistrally sequencing the pairs of the same-case marked NPs of same or different type. We further show that, while the nominative case marker is shared between two consecutive NPs standing in one of the 16 semantic relations, multiplication of the accusative case marker is possible between two consecutive NPs standing in only one of the 10 semantic relations.

Some appealing consequences of this proposal include a new comprehensive classification of the sequences of identical case-marked NPs and a straightforward account of some long standing problems such as how an additional samecase NPs are licensed, in what respects the multiple nominative marking and the multiple accusative marking are alike and different from each other, how only some subsets of sequences of same-case NPs are possible, and why the order of the NPs in the sequences of same-case NPs should be strictly preserved. 


\section{Bibliography}

Bak, Jung-Sup. 1992. Multiple subjects and multiple objects. In Studies in Generative Grammar 2. 293-334. Written in Korean.

Cha, Jong-Yul. 2008. A typology of double nominative constructions in Korean. Ms., Paper presented at the 18th International Congress of Linguists (SIL XIII), Seoul, Korea.

Chae, Hee-Rahk \& Ilkyu Kim. 2008. A clausal predicate analysis of Korean multiple nominative constructions. Korean fournal of Linguistics 33. 869-900.

Cho, Sae-Youn. 1999. The syntactic structure of some double nominative constructions in Korean. Linguistics 7. 335-348.

Cho, Sungeun. 2003. A conditioning factor in possessor agreement constructions. In Patricia M. Clancy (ed.), Japanese/Korean linguistics, vol. 11, 343-351. Stanford: CSLI Publications.

Cho, Wonbin \& Sungeun; Lee. 2003. Possessor agreement as Theta feature sharing. Language and Information 7. 163-178.

Choe, Hyun-Sook. 1987. Syntactic adjunction, A-chains, and multiple identical case constructions. In Joyce McDonough \& Bernadette Plunkett (eds.). Proceedings of North Eastern Linguistic Society (NELS), vol. 17, 100-121.

Choi, Incheol. 2007. A constraint-based approach to Korean inalienable possession constructions. Studies in Modern Grammar 47. 95-115. Stanford: CSLI Publishing.

Choi, Incheol. 2012. Sentential specifiers in the Korean clause structure. In Stefan Müller (ed.), Proceedings of the 19th international conference on headdriven phrase structure grammar, 75-85.

Choi, Kiyong. 2008. Two types of double nominative constructions in Korean: A case of GEN/NOM alternation. Korean fournal of Linguistics 33, 901-928.

Choi, Young-Seok. 1988. A study of possessor ascensions construction in Korean, Doctoral dissertation. University of Hawaii dissertation.

Cruse, D. A. 1979. On the transitivity of the part-whole relation. Fournal of Linguistics 15, 29-38.

Cruse, D. A. 1986. Lexical semantics. Cambridge: Cambridge University Press.

Gerdts, D. 1991/2000. The syntax of case-marked possessors in Korean. In John Whitman \& Chungmin Lee (eds.), Korean syntax and semantics LSA institute workshop, Santa Cruz 1991, 19-34. Seoul: Taehaksa.

Hong, Ki-Sun. 1991. Argument selection and case-marking in Korean: Stanford University dissertation. Doctoral dissertation. 
Hong, Yong-Tcheol. 2001. Structure des constructions à sujet multiple. Enseignement de Langue et Littérature Françaises 11, 159-183. Written in Korean.

Iris, M. A., B. E. Litowitz \& M. Evens. 1988. Problems of the part-whole relation. In M. Evens (ed.), Relational models of the lexicon, 261-288. Cambridge: Cambridge University Press.

Jang, Youngjun. 1998. Multiple subjects and characterization. Discourse and Cognition 5, 99-116.

Kang, Myung-Yoon. 1987. Possessor raising in Korean. In Susumu Kuno et al. (eds.), Harvard studies in Korean linguistics, vol. II, 80-88. Seoul: Hanshin Publishing Company.

Kim, Jong-Bok. 2000. A constraint-based approach to some multiple nominative constructions in Korean. In Akira Ikeya \& Masahito Kawamori (eds.), Proceedings of the 14th pacific asia conference on language, information, and computation, 165-176. Toyko: Logico-Linguistic Society of Japan.

Kim, Jong-Bok. 2001. A constraint-based and head-driven analysis of multiple nominative constructions. In D. Flickinger \& A. Kathol (eds.), Proceedings of the 7th international conference on head-driven phrase structure grammar, 166-181. Stanford: CSLI Publishing.

Kim, Jong-Bok, P. Sells \& Jaehyung Yang. 2007. Parsing two types of multiple nominative construction: A constructional approach. Language and Information 11, 25-37.

Kim, Kwang-sup. 1996. Multiple subject constructions in Korean and English. In Hee-Don Ahn et al. (eds.), Morphosyntax in generative grammar, 235-249. Seoul: Hanguk Publishing Company.

Kim, Yong-Ha. 2006. A case for ellipsis in Korean: The non-movement multiple object construction. In Studies in generative grammar 16, 707-742.

Kim, Young-joo. 1989. Inalienable possession as a semantic relationship underlying predication: The case of multiple-accusative constructions. In Susumu Kuno et al. (eds.), Harvard studies in Korean linguistics, vol. III, 445-467. Seoul: Hanshin Publishing Company.

Kim, Young-joo. 1990. The syntax and semantics of Korean case: The interaction between lexical and syntactic levels of representation. Doctoral dissertation. Harvard University.

Koh, Jae-Sol. 1999. Multiple nominative constructions and the inner subjects of adjectives. Korean fournal of Linguistics 24, 531-556. Written in Korean. 
Lee, Chungmin. 1994. Definite/specific and case marking in Korean. In Young-Key Kim-Renaud (ed.), Theoretical issues in Korean linguistics, 345-361. Stanford: CSLI Publications.

Lee, Hyeran. 2008. Criterial effects and multiple nominative constructions. In Studies in generative grammar 18. 477-508.

Lee, Seong-yong. 2007. Two subject positions in multiple nominative constructions. Journal of Language Sciences 14, 239-262.

Lee, Wonbin \& Sungeun Cho. 2003. Case agreement in possessive constructions. In Studies in generative grammar, vol. 13, 633-655. Walter de Gruyter.

Lyons, J. 1977. Semantics, vol. 1. Cambridge: Cambridge University Press.

Maling, J. \& Soowon Kim. 1992. Case assignment in the inalienable possession construction in Korean. Journal of East Asian Linguistics 1, 37-68.

Miller, G. A. \& P. N. Johnson-Laird. 1976. Language and perception. Cambridge, MA: Harvard University Press.

Moon, Gui-Sun. 2000. The predication operation and multiple subject constructions in Korean. In Studies in generative grammar 10. 239-263.

Na, Younghee \& G. J. Huck. 1993. On the status of certain island violations in Korean. Linguistics and Philosophy 16, 181-229.

O’Grady, W. 1991. Categories and case. Amsterdam: John Benjamins Publishing.

Park, Byung-Soo. 2001. Constraints on multiple nominative constructions in Korean: A constraint-based lexicalist approach. The fournal of Linguistic Science 20, 147-190.

Rhee, Seongha. 1999. On the multiple nominative constructions in Korean. In Young-Wha Kim, Il-Kon Kim \& Jeong-Woon Park (eds.), Linguistic investigations: In honor of professor In-Seok Yang, 198-430. Seoul: Hankuk Publisher.

Ryu, Byong-Rae. 1993. Structure sharing and argument transfer: An HPSG approach to verbal noun constructions. SfS-Report 04-93. Seminar für Sprachwissenschaft, University of Tübingen.

Schütze, C. 1996. Korean case stacking isn't: Non-case uses of case particles. In Kiyomi Kusumoto (ed.), Proceedings of the North East Linguistic Society, vol. 26, 351-365.

Schütze, C. T. 2001. On Korean 'case stacking': the varied functions of the particles ka and lul. The Linguistic Review 18, 193-232.

Suh, Sangki. 2003. The distribution of multiple subject constructions in Korean. Language Research 39, 839-857. 
Whitman, J. 1991/2000. Adjunct major subjects in Korean. In J. Whitman \& Chungmin Lee (eds.), Korean syntax and semantics LSA institute workshop, Santa Cruz 1991. 1-8. Seoul: Taehaksa.

Winston, M., R. Chaffin \& D. Hermann. 1987. A taxonomy of part-whole relations. Cognitive Science 11, 417-444.

Yang, In-Seok. 1972. Korean syntax: Case markers, delimiters, complementation and relativization. Doctoral Dissertation. The University of Hawaii.

Yim, Young-Jae. 1984. The syntactic nature of the multiple subject construction. Language Research 20, 321-330.

Yoon, J. H. 1987. Some queries concerning the syntax of multiple subject constructions in Korean. In Susumu Kuno et al. (eds.), Harvard studies in Korean linguistics, vol. II, 138-162. Seoul: Hanshin Publishing Company.

Yoon, J. H. 1989. The grammar of inalienable possession construction in Korean, Mandarin and French. In Susumu Kuno et al. (eds.), Harvard studies in Korean linguistics, vol. III, 357-368. Seoul: Hanshin Publishing Company.

Yoon, J. H. 2004. Non-nominative (major) subjects and case-stacking in Korean. In P. Bhaskararao \& K. V. Subbarao (eds.), Non-nominative subjects, vol. 2, 265-314. Berlin: Mouton de Gruyter.

Yoon, J. H. 2007. The distribution of subject properties in multiple subject constructions. In Y. Takubo (ed.), Japanese/Korean linguistics, vol. 16, 64-83. Stanford: CSLI Publications.

Yoon, Jeong-Me. 1997. The argument structure of relational nouns and inalienable possessor constructions in Korean. Language Research 33, 231-265.

Youn, Cheong. 1990. A relational analysis of Korean multiple nominative constructions. Seoul: Hanshin Publishing Company.

Yu, Kil-chun. 1909. Tayhanmuncen (Korean Grammar, written in Korean). Yungmunkwan.

\section{Author}

Byong-Rae Ryu

Department of Linguistics

Chungnam National University, South Korea

ryu@cnu.ac.kr 